\title{
Molecular epidemiology and clinical features of hand, foot and mouth disease in northern Thailand in 2016: a prospective cohort study
}

Panupong Upala ${ }^{1,2}$, Tawatchai Apidechkul ${ }^{1,2^{*}}$, Wipob Suttana ${ }^{1,2}$, Niwed Kullawong ${ }^{1,2}$, Ratipark Tamornpark ${ }^{1,2}$ and Chadaporn $\operatorname{lnta}^{2}$

\begin{abstract}
Background: Hand, foot and mouth disease (HFMD) is a major communicable disease in children $\leq 6$ years old, particularly in several countries in the Asia-Pacific Region, including Thailand. HFMD impacts public health and the economy, especially in northern Thailand.

Methods: A prospective cohort study was conducted to estimate the incidence rate and to identify the serotype and clinical features of HFMD among children in northern Thailand. A validated questionnaire and throat swab were used for data collection. Polymerase chain reaction (PCR) was used to detect human enterovirus and identify its serotypes. Participants were recruited from 14 hospitals in two provinces in northern Thailand, specifically, Chiang Rai and Pha Yao Province, between January 1, 2016, and December 31, 2016. Chi-square or Fisher's exact test was used to detect the associations of signs and symptoms with HFMD serotype. Logistic regression was used to detect the associations of variables with a positive enterovirus at alpha $=0.05$.

(Continued on next page)
\end{abstract}

\footnotetext{
* Correspondence: Tawatchai.api@mfu.ac.th; tk2516ms@gmail.com

${ }^{1}$ Center of Excellence for the Hill-tribe Health Research, Mae Fah Luang

University, 333 Mo.1 Tasud Subdistrict, Muang District, Chiang Rai, Chiang Rai

Province 57100, Thailand

${ }^{2}$ School of Health Science Research, Mae Fah Luang University, 333 Mo.1

Tasud Subdistrict, Muang District, Chiang Rai, Chiang Rai Province 57100,

Thailand
}

(c) The Author(s). 2018 Open Access This article is distributed under the terms of the Creative Commons Attribution 4.0 International License (http://creativecommons.org/licenses/by/4.0/), which permits unrestricted use, distribution, and reproduction in any medium, provided you give appropriate credit to the original author(s) and the source, provide a link to the Creative Commons license, and indicate if changes were made. The Creative Commons Public Domain Dedication waiver (http://creativecommons.org/publicdomain/zero/1.0/) applies to the data made available in this article, unless otherwise stated. 
(Continued from previous page)

Result: In total, 612 children aged $\leq 6$ years from Chiang Rai and Pha Yao Province who were diagnosed with HFMD by a throat swab were recruited for the analysis. Approximately half of the cohort was male (57.2\%), 57.5\% was aged $<2$ years, and 57.5\% lived in rural areas. The incidence rate was 279.72/100,000 person-years in Chiang Rai Province and 321.24 per 100,000 person-years in Pha Yao Province. Additionally, 42.5\% of children were positive for human enterovirus; among these children, 56.1\% were positive for enterovirus-A (EV-A), 17.7\% were positive for coxsackievirus (CV), and 26.2\% were positive for other human RNA enteroviruses. During the study period, 21 distinct outbreaks of HFMD were recognized. Four to five patients (total 92 patients) were selected from each outbreak for identifying its serotype; enterovirus-A71 (EV-A71) was detected in 34.8\% of HFMD cases, coxsackievirus-A16 (CV-A16) in 26.1\%, coxsackivirus-A6 (CV-A6) in 15.2\%, coxsackievirus-A10 (CV-A10) in 10.9\%, coxsackievirus-A4 (CV-A4) in 2.2\%, coxsackievirus-B2 (CV-B2) in $2.2 \%$, human rhinovirus in 2.2\%, and unknown serotype in 6.4\%. Multivariable analysis demonstrated that a history of breastfeeding for $\leq 6$ months was associated with a higher chance of enterovirus infection than a history of breastfeeding $>6$ months, and children who had mother who worked as farmers, daily wage employees, and unprofessional skilled jobs had a greater chance of enterovirus infection than those who had unemployed mothers. Coxsackievirus-infected children had a higher rate of rashes on the buttocks, knee, and elbow and fever but a lower rate of lethargy and malaise than EV-A71-infected children.

Conclusions: EV-A71 is a major cause of HFMD in children < 6 years old in northern Thailand, but rash, fever, and mouth ulcers are mostly found in participants with coxsackievirus infection. Breastfeeding should be promoted during early childhood for at least 6 months to prevent HFMD particularly those mother who are working in unprofessional skill jobs.

Keywords: Hand, Foot and mouth, Molecular epidemiology, Clinical feature, Serotype, EV-A71, Coxsackievirus

\section{Background}

Recently, hand, foot and mouth disease (HFMD) has been defined as a new public health threat with large-scale infections, especially in children who are living in the Asia-Pacific Region, including Thailand [1]. Personal hygiene, sanitation and meteorological factors, such as environmental temperature, wind speed, air pressure, relative humidity and rainfall amount, have been associated with epidemic diseases [2-5]. HFMD is caused by various human enteroviruses, such as enterovirus A71 (EV-A71), coxsackievirus A16 (CV-A16), CV-A6, and CV-A10. Different serotypes predominate in different regions [6-9] and present different severities of clinical signs and symptoms after disease onset, such as fever, reduced appetite, sore throat, painful sores in the mouth, a rash of flat red spots, headache, stiff neck, and death [10, 11]. The World Health Organization (WHO) reported that children aged $<6$ years and living in crowded areas are a vulnerable population for HFMD. Various episodes of HFMD have been reported in different parts of the world [12]. There are limited treatment modalities for HFMD, but several licensed vaccines are available for EV-A71 [13-18].

Every year, a large number of HFMD cases are reported globally. In 2016, the WHO reported 69,121 cases of HFMD in Japan. In total, 2,468,174 cases were reported in China, with 220 deaths in 2016. Singapore reported 42,147 cases in 2016, and Vietnam reported 48,866 cases in the same year [19].

In 2017, the Bureau of Epidemiology at the Ministry of Public Health of Thailand reported that 70,377 patients (prevalence proportion was $107.57 / 100,000$ population) were diagnosed with HFMD, including 3 deaths. The Ministry of Public Health also reported that the ratio of male to female patients with HFMD was 1:0.80, and $25.90 \%$ of those patients were less than one year old. Northern Thailand was recognized as having the highest prevalence of HFMD in Thailand at 129.06/100,000 population, while the overall national incidence rate of HFMD in 2016 was 78.46/100,000 person-years [20]. The number of HFMD cases varied according to the sex, age, and socioeconomic status of a population; there were more HFMD cases among males than among females, more patients with lower age than older age, and more patients with low economic status than high economic status [20]. Piyada et al. [21] reported that there were some differences in the serotype of HFMD in different regions of Thailand.

Northern Thailand is geographically unique; 70\% of the areas are mountainous, with relatively low temperatures throughout the year compared to other regions of Thailand. Chiang Rai and Pha Yao provinces are located in the northernmost area of Thailand bordering Myanmar, Republic of Lao, and China. In 2017, approximately 1.3 million people lived in Chiang Rai Province, and 490,000 people lived in Pha Yao Province. Among these populations, $25-30 \%$ are classified as an ethnic minority. Approximately $85 \%$ of the population in the two provinces had access to health care under universal coverage schemes in which medical expenses are free of charge [22]. The remaining part of the population did not meet the requirements to access health care services free of charge because they did not have a national 
identification card (ID) card. In Thailand, a national identification card (ID) is required for free or subsidized government medical services. Approximately one-third of the population lives below the national poverty level [23-26]. Most ethnic minorities are recognized as low socioeconomic populations in Thailand [27]. Conditions such as geographical location, socioeconomic status and ethnicity were suspected to contribute to the different patterns of HFMD serotype in children and to impact the severity of clinical features of infected children. Most children were left in a day care center (DCC) during the day time $[28,29]$. Inta et al. reported that the most vulnerable population for HFMD in northern Thailand was children who attended DCCs, and there are numerous outbreaks in DCCs during the early rainy season of the year [29]. Concerns about HFMD are related to not only treatment and care but also medical expenses through the health care system. Upala et al. reported that 7 USD (216 baht) and 115 USD (3678 baht) were spent per patient per visit for HFMD medical costs and diagnosis in outpatient departments (OPD) and inpatient departments (IPD), respectively [30].

The objectives of this study were to conduct a comprehensive evaluation of HFMD epidemiology and to determine the molecular characteristics related to clinical features to test associations among a specific large-scale cohort in the highest epidemic areas, such as the northern areas of Thailand bordering Myanmar, Republic of Lao, and China (See Fig. 1).

\section{Methods}

\section{Study design}

A prospective cohort study was conducted to estimate the incidence rates, which were calculated by the number of new cases divided by the total number of children aged less than 6 years in the area for one year; to identify the dominant serotypes and their associations with clinical features; and to assess the risk factors for enteroviruses that cause HFMD among children less than 6 years old.

\section{Study sites}

Data were collected from 14 hospitals in Chiang Rai and Pha Yao Province: 10 hospitals in Chiang Rai Province, and 4 hospitals in Pha Yao Province. In 2016, there were 16 hospitals in Chiang Rai Province and 6 hospitals in Pha Yao Province. However, the remaining 8 hospitals did not report HFMD cases during the study period.

\section{Study population}

Children $\leq 6$ years old living in Chiang Rai and Pha Yao provinces and diagnosed with HFMD between January 1, 2016, and December 31, 2016, from 14 hospitals where at least one case of HFMD was reported were included in the study.

\section{Study sample}

All patients from each episode of an HFMD outbreak in Chiang Rai and Pha Yao provinces from whom a throat swab was obtained during the study period and in one of the 14 hospitals were selected as the study sample. An average of 10-15 patients in each outbreak were recruited. The first to the 10th-15th patient of each outbreak was recruited into the study with a purposive method which was based on the report at 10-15 HFMD cases in each outbreak in Thailand [31].

\section{Case definition}

Children $\leq 6$ years old attending one of the 14 hospitals in Chiang Rai and Pa Yao provinces who were diagnosed with HFMD by a medical doctor between January 1, 2016, and December 31, 2016, were included. All medical doctors in the study areas, including the 14 hospitals, used clinical signs under the International Classification of Diseases (ICD-10) system with code $\mathrm{BP}$ 08.4 [32] as the principle criteria for HFMD diagnosis.

\section{Case diagnosis}

HFMD diagnosis was performed using clinical signs and laboratory testing according to the standard protocol of the WHO, 2015 [1]. All medical doctors in Thailand were encouraged to use this standard guideline for HFMD case diagnosis and management.

\section{Outbreak}

An outbreak is the occurrence of more cases of a disease than would normally be expected in a specific place or group of people over a given period of time [33].

\section{Outbreak detection}

All public hospitals in Thailand have a surveillance system that networks between physicians and public health professionals, including epidemiologists. This system is operated by the Bureau of Epidemiology in the Ministry of Public Health [34]. The system is connected throughout the country. When an HFMD case was diagnosed by a physician, the diagnosis was sent to the epidemiology unit in the hospital. A case was then reported through the surveillance system network. The Epidemiology Department at the Provincial Public Health Office responds to the system and is alerted when there is an abnormal situation or when the mean number of HFMD cases is the mean of those in three previous years plus 2 standard deviation, which is the criteria for an outbreak and is commonly used in all healthcare settings in Thailand [34]. 


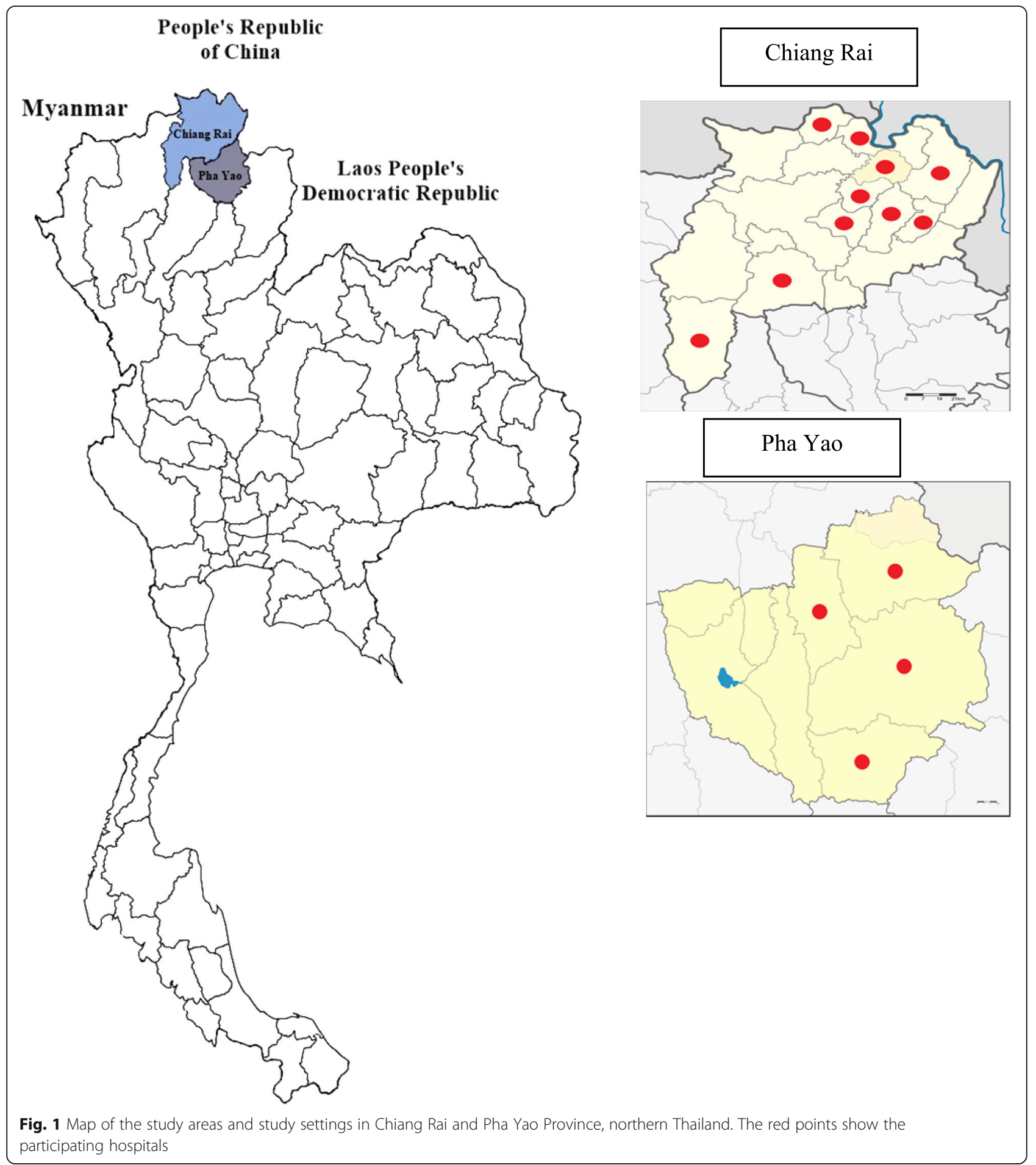

\section{Case recruitment}

In the first step, throat swabs were collected from 612 patients recruited into the study with an early diagnosis of HFMD by a medical doctor. All selected patients were asked to complete a questionnaire, and specimens were collected. In this step, the running number from the first case to the last case of each outbreak was labeled on both the questionnaires and tubes. The specimens were sent to the laboratory to identify human enteroviruses.

In the second step, 4-5 early cases in each outbreak labeled with running numbers from the first step that tested positive for human enterovirus species were selected to identify the serotype by a purposive method. 


\section{Research instruments}

A specific questionnaire was developed and used for data collection. There were 25 questions within 3 parts. In the first part, 14 questions were used to collect general information about the children, such as age; sex; weight; height; history of breast feeding; daytime care; congenital diseases, such as thalassemia, allergy, asthma, and G-6-PD (glucose-6-phosphate dehydrogenase deficiency); history of vaccination by the National Expanded Program of Immunization (EPI), as children who had been vaccinated were healthier than those who had not been vaccinated and were at lower risk of infection; group activity with other children in their village prior to infection; and history of receiving an HFMD diagnosis by a medical doctor. In the second part, 8 questions were used to collect the characteristics of parents and caregivers, such as marital status, occupation, education, and whether they were the major care giver. In rural Thailand, major caregivers are often not parents but could be a grandfather or grandmother. In the last part, 4 questions were used to collect information regarding the illness, such as the start date and end date of the illness, signs and symptoms, and details of changes during the course of the illness, referring to all signs and symptoms that changed from the start of the illness to the end of the illness.

The questionnaire (Additional file 1) was tested for reliability by the test-retest method. The validity of the questionnaire was determined by the item-objective congruence technique (IOC). A pilot study including 10 selected samples with characteristics similar to those of the target population was conducted before the questionnaire was used in the present study.

Sterile viral transport medium was used for specimen collection by trained doctors in each hospital. Throat swabs were obtained from participants. The virus serotype was detected using a molecular method at Chiang Rai Medical Science Laboratory Center.

\section{Specimen and data collection procedures}

Access to hospitals was granted by the Chiang Rai and Pha Yao Provincial Public Health Officers. Hospital directors and relevant staff were asked to participate in the project. The methods of collecting specimens and completing the questionnaires were demonstrated to physicians, nurses, and medical technician staff who were working in the 14 hospitals before commencement of the project.

Once the outbreak was reported, the parents of all HFMD patients from outpatient (OPD) or inpatient (IPD) departments whose patients could provide a throat swab were invited to participate in the study. All invited parents were asked to provide written informed consent on behalf of their children. With consent from the parents, a physician filled out the questionnaire and performed a throat swab using the material provided, with assistance from a trained nurse or laboratory technician. Specimens were stored in a refrigerator at the hospital and were ready for transfer to the Chiang Rai Medical Laboratory Center for laboratory work the next day.

\section{Sample storage, transportation, and EV detection}

Specimens were stored in sterile viral transport medium and transported to the Chiang Rai Medical Science Laboratory Center the next day. The samples were stored until a sufficient number of samples for batch testing was reached. Below are the five steps for molecular genome identification of enterovirus and its subspecies (Fig. 2).

The first step was to extract enterovirus RNA from the specimens. Total RNA was extracted from all specimens using NucleoSpin ${ }^{\circ}$ Virus (Pacific Science Co., LTD).

The second step was to synthesize first-strand cDNA for each sample. A volume of $5 \mu \mathrm{l}$ of extracted total RNA was used as a template for first-strand cDNA synthesis (SuperScript $^{\text {tin }}$ III Reverse Transcriptase, Invitrogen) with $1 \mathrm{X}$ First-Strand buffer, conserved amino acid sequence-specific primers (AN32, 5'-GTY TGC CA-3'; AN33, 5'-GAY TGC CA-3'; AN34, 5'-CCR TCR TA-3'; AN35. 5'-RCT YTG CCA-3'), 10 mM DTT, 0.2 units/ $\mu$ l RNaseOUT ${ }^{\text {Tx }}$ Recombinant RNase Inhibitor, and 10 units/ $\mu$ l of SuperScript ${ }^{\text {tix }}$ III RT in a final volume of $20 \mu \mathrm{l}$ [35].

The third step was to identify the infection-causing enterovirus using the multiplex PCR technique. For a total reaction volume of $50 \mu \mathrm{L}, 3 \mu \mathrm{L}$ of synthesized first-strand cDNA was used as a template for PCR amplification with 1X PCR buffer (HotStarTaq DNA polymerase Kit, QIAGEN), $\quad 400 \mu \mathrm{M}$ dNTPs, $0.4 \mu \mathrm{M}$ enterovirus primers (SO222R, 5'-CIC CIG GIG GIA YRW ACA T-3'; SO224, 5'-GCI ATG YTI GGI ACI CAY RT-3'), 1X Q-Solution and 2.5 units HotStarTaq DNA polymerase [36]. PCR was conducted in a $\mathrm{T}_{100}{ }^{\text {tix }}$ Thermal Cycler (Bio-Rad) and started with an initial denaturation step at $95^{\circ} \mathrm{C}$ for $5 \mathrm{~min}$ followed by 40 cycles of $95^{\circ} \mathrm{C}$ for $30 \mathrm{~s}, 48^{\circ} \mathrm{C}$ for $30 \mathrm{~s}$ and $72^{\circ} \mathrm{C}$ for $45 \mathrm{~s}$, ending with a final extension step at $72^{\circ} \mathrm{C}$ for $7 \mathrm{~min}$.

Positive specimens were sent for detection in the fourth step. This step aimed to classify the EV-A71 or Coxsackievirus. A similar reaction was set up with different pairs of primers: $2 \mu \mathrm{M}$ each CA16 primer (T79F, 5'-CCT ACM GCY GCC AAY ACY RAW GC-3'; T314R, 5'-CCA TCK GTG TTY TGK GTR CC-3') or $2 \mu \mathrm{M}$ each EV71 primer (T001F, 5'-ACY ATG AAA YTG TGC AAR G-3'; T002R, 5'-CCR GTR GGI GTR CAY GCA AC-3') with the same annealing temperature of $48^{\circ} \mathrm{C}$.

In the final step, 92 specimens (4-5 cases from each episode of an outbreak) were purposively selected from the early cases (Case No.1st to case No. 5th) of each outbreak 


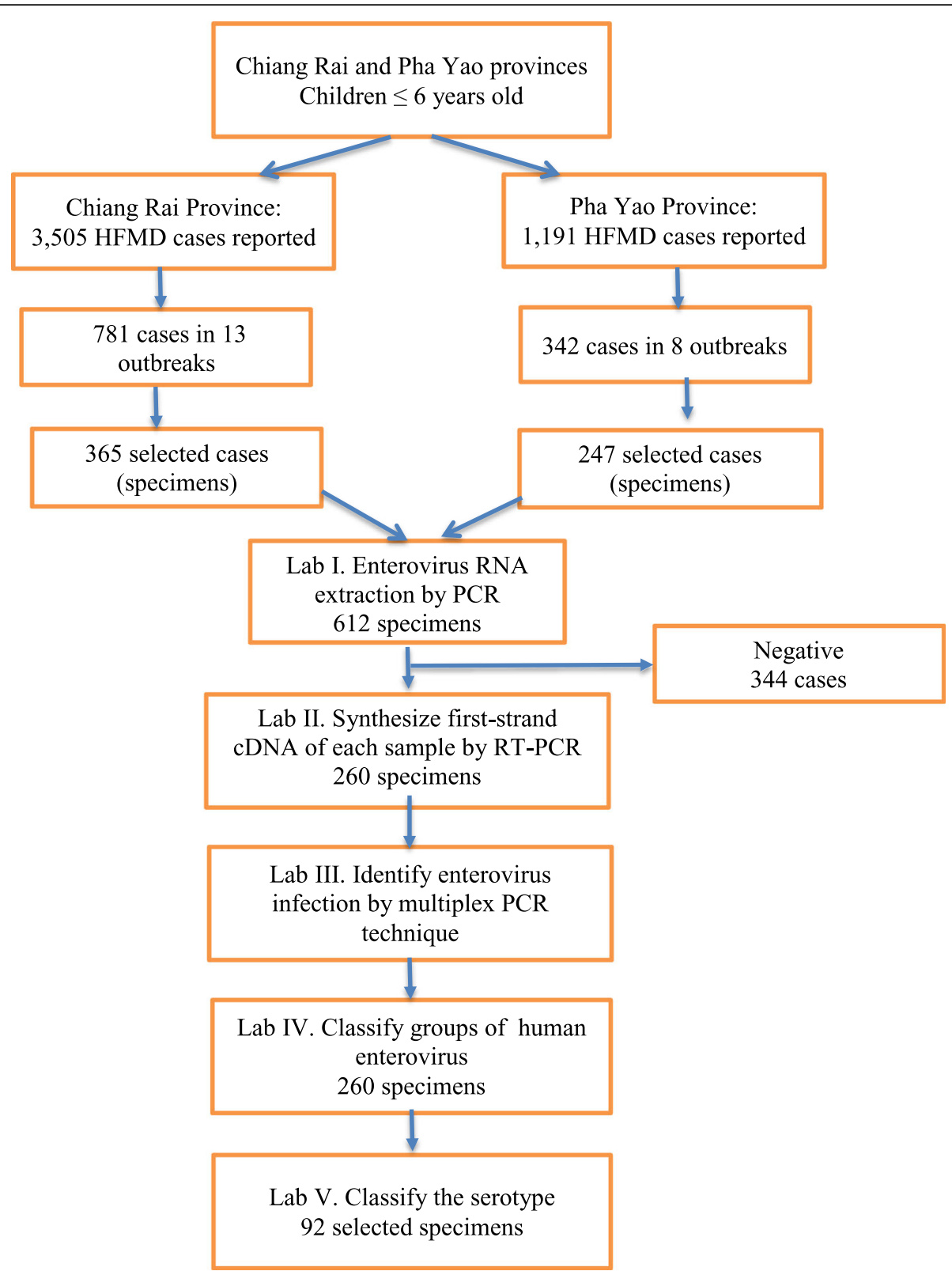

Fig. 2 Steps of data collection and laboratory analysis from two settings; Chiang Rai and Pha Yao Province. In total, 4696 cases of HFMD from two Provinces were reported in 2016. 612 cases from 21 outbreaks were recruited into the study. Among them, 260 were positive for human enterovirus. 92 selected specimens were detected the serotyping

for genome identification by commercial automated DNA sequencing. The serotype was identified after serotyping by similarity searches and BLAST searches. Data from the questionnaires and laboratory results were merged for statistical analysis (Fig. 2).

\section{Statistical analysis}

Microsoft Excel was used for double entry and data validation. Data were analyzed by SPSS version 24, 2016 (SPSS, Chicago, IL). Both descriptive and inferential statistics were used to describe the general characteristics of participants and to test the associations between variables. Chi-square test or Fisher's exact test was used to detect the associations of clinical features with the serotype of HFMD. Logistic regression was used to identify the factors associated with HFMD. The "ENTER" mode was used to detect associations in both the univariate and multivariable steps. All significant variables in the univariate analysis were subsequently used in the multivariable analysis to 
Table 1 General characteristics of HFMD patients

\begin{tabular}{lll}
\hline Characteristic & $n$ & $\%$ \\
\hline Total & 612 & 100.0 \\
Province & & \\
$\quad$ Chiang Rai & 365 & 59.6 \\
$\quad$ Pha Yao & 247 & 40.4 \\
Season & & \\
$\quad$ Summer (November-February) & 102 & 16.7 \\
$\quad$ Rainy (June-October) & 317 & 51.8 \\
Cold (March-May) & 193 & 31.5 \\
Sex & & \\
$\quad$ Male & 350 & 57.2 \\
$\quad$ Female & 262 & 42.8 \\
Age (years) & & \\
$\quad<2$ & 352 & 57.5 \\
2-3 & 146 & 23.9 \\
$\quad$ 3 & 114 & 18.6 \\
Residential area & & \\
Rural & 352 & 57.5 \\
Municipal & 260 & 42.5 \\
Patipated a & &
\end{tabular}

Participated in a group activity 2 weeks prior to disease onset

$\begin{array}{lll}\text { No } & 138 & 22.6 \\ \text { Yes } & 474 & 77.4\end{array}$

Type of attendance in a hospital

$\begin{array}{lll}\text { Outpatient } & 532 & 86.9 \\ \text { Inpatient } & 80 & 13.1 \\ \text { History of breastfeeding } & & \\ \text { No breastfeeding } & 24 & 3.9 \\ \leq 6 \text { months } & 224 & 36.6 \\ >6 \text { months } & 364 & 59.5 \\ \text { Vaccination history } & & \\ \text { Complete and timely } & 562 & 91.8 \\ \text { Incomplete and/or not timely } & 50 & 8.2\end{array}$

Place of daytime care

Home

Day care center

Children's school

Congenital disease

No

G6PD

Allergy

Thalassemia

Asthma

Number of family members (persons)

$$
<4
$$$$
\text { 4-7 }
$$

Table 1 General characteristics of HFMD patients (Continued)

\begin{tabular}{lcl}
\hline Characteristic & $n$ & $\%$ \\
\hline$>7$ & 52 & 8.5 \\
$\begin{array}{l}\text { Number of family members aged } \\
\quad<2\end{array}$ & 58 years old (persons) & \\
$\quad 2$ & 28 & 95.4 \\
$>2$ & & 4.6 \\
History of HFMD in the previous year & 534 & \\
No & 78 & 87.3 \\
Yes & 72.7 \\
\hline
\end{tabular}

establish the final fixed model. The alpha was set at 0.05 in both the univariate and multivariable analyses (Additional file 2).

\section{Results}

In total, 3505 cases of HFMD from Chiang Rai Province and 1191 cases from Pha Yao Province were reported in 2016. Twenty-one outbreaks were reported through the public health surveillance system in these two provinces between January 1, 2016, and December 31, 2016: 13 outbreaks from Chiang Rai Province, and 8 outbreaks from Pha Yao Province. Seven hundred and eighty-one (781) cases of HFMD that were reported from 13 outbreaks in Chiang Rai Province accounted for 22.3\% of reported cases in the entire year. Three hundred forty-two (342) cases reported from 8 outbreaks in Pha Yao Province accounted for $28.7 \%$ of the reported cases in the entire year. The incidence rates of HFMD were 279.72/100,000 person-years in Chiang Rai Province and 321.24/100,000 person-years in Pha Yao Province (Fig. 2).

Throat swabs were obtained for 612 out of 1123 patients (54.5\%), and those patients were recruited into the study: 59.6\% were from Chiang Rai Province (365 patients), $51.8 \%$ were ill in the rainy season, $57.2 \%$ were males, and the majority were under 2 years old (57.5\%) and lived in rural areas (57.5\%). The average time from the onset of the illness to the end of its course was 4.04 days $(\min =2$ days, $\max =7$ days); patients positive for EV-A71 had a longer duration of illness than other patients (mean 5.20 days), and the average number of days after the onset of disease before a visit to a doctor was 1.70 days ( $\min =1$ day, $\max =6$ days). One-quarter of the patients had participated in a group activity before disease onset, and most patients presented to the hospitals as outpatients (86.9\%). Almost half of the patients were breastfed by their mothers for less than 6 months (40.5\%). Additionally, $8.2 \%$ of patients were vaccinated with an incomplete schedule, $4.6 \%$ had a family member who was less than 6 years old, and $12.7 \%$ had been diagnosed with HFMD in the previous year (Table 1).

Regarding the characteristics of parents, $88.9 \%$ were married, and $98.0 \%$ were Buddhist. Almost half of the 
fathers $(49.4 \%)$ and $37.8 \%$ of mothers worked as a daily wage employee in an unprofessional work sector. More than half of the caregivers (57.5\%) were uneducated or studied below the primary school level (Table 2).

In total, 612 patients with a diagnosis of HFMD were selected to undergo specimen collection for laboratory detection. Only $42.5 \%$ of those patients were positive for human enterovirus. Among patients who were positive for human enterovirus, $17.7 \%$ tested positive for coxsackievirus, $56.1 \%$ for EV-A71, and $26.2 \%$ for other human RNA enteroviruses.

Table 2 General characteristics of parents' of HFMD patients

\begin{tabular}{|c|c|c|}
\hline Characteristic & $n$ & $\%$ \\
\hline Total & 612 & 100.0 \\
\hline \multicolumn{3}{|l|}{ Marital status } \\
\hline Single & 18 & 2.9 \\
\hline Married & 544 & 88.9 \\
\hline Widow and divorce & 50 & 8.2 \\
\hline \multicolumn{3}{|l|}{ Religion } \\
\hline Buddhism & 600 & 98.0 \\
\hline Christianity & 12 & 2.0 \\
\hline \multicolumn{3}{|l|}{ Father's occupation } \\
\hline Unemployed & 66 & 10.8 \\
\hline Government employee & 24 & 3.9 \\
\hline Farmer & 142 & 23.2 \\
\hline Daily-wage employee & 302 & 49.4 \\
\hline Unprofessional skilled job & 78 & 12.7 \\
\hline \multicolumn{3}{|l|}{ Mother's occupation } \\
\hline Unemployed & 168 & 27.5 \\
\hline Government employee & 18 & 2.9 \\
\hline Farmer & 108 & 17.7 \\
\hline Daily-wage employee & 232 & 37.8 \\
\hline Unprofessional skilled job & 86 & 14.1 \\
\hline \multicolumn{3}{|l|}{ Major caregiver } \\
\hline Father & 14 & 2.3 \\
\hline Mother & 346 & 56.5 \\
\hline Relative & 202 & 33.0 \\
\hline Father and mother & 50 & 8.2 \\
\hline \multicolumn{3}{|l|}{ Education of caregiver } \\
\hline Not educated & 174 & 28.4 \\
\hline Primary school & 178 & 29.1 \\
\hline Secondary school & 82 & 13.4 \\
\hline High school & 108 & 17.7 \\
\hline Vocational and higher & 70 & 11.4 \\
\hline \multicolumn{3}{|c|}{ Daily cleaning of food and drink containers } \\
\hline No & 32 & 5.2 \\
\hline Yes & 580 & 94.8 \\
\hline
\end{tabular}

Among 92 patients who were positive for human enterovirus, 4-5 patients from each outbreak were further analyzed to identify the serotype. The results indicated that $34.8 \%$ of patients were positive for EV-A71, 26.1\% for CV-A16, 15.2\% for CV-A6, 10.9\% for CV-A10, and $2.2 \%$ for human enterovirus (Table 3 ).

In the multivariable analysis of the factors associated with positive enterovirus detection among the $612 \mathrm{pa}-$ tients, the following two variables had significant associations: history of breastfeeding and occupation of mother. Children who had never been breastfed and those with a history of breastfeeding $\leq 6$ months had a 3.74-fold (95\% $\mathrm{CI}=1.53-9.10)$ and 2.52 -fold $(95 \% \mathrm{CI}=1.76-3.61)$ greater chance of suffering from EV-associated HFMD than children who had a history of breastfeeding $>6$ months, respectively. Children who had mother who worked as farmers, daily wage employee, and unprofessional skilled job had a 1.88 -fold (95\% CI $=1.11-3.16), 2.18$-fold $(95 \%$ $\mathrm{CI}=1.41-3.37), \quad$ and $\quad 2.64$-fold $\quad(95 \% \quad \mathrm{CI}=1.52-4.61)$ greater chance of EV-associated HFMD than children who had mother as unemployed, respectively (Table 4).

Five clinical features were associated with different serotypes among 576 cases (36 missing, accounted for $5.8 \%)$. Patients with coxsackievirus and other human enteroviruses had a greater chance of having a rash on their buttocks, knees, and elbows, having a fever, and sore throat or mouth ulcer than those with EV-A71. Those with coxsackievirus had a greater chance of

Table 3 Serotype data of the HFMD patients

\begin{tabular}{lll}
\hline Type & $n$ & $\%$ \\
\hline Total & 612 & 100.0 \\
Human enterovirus species & & \\
$\quad$ Negative & 352 & 57.5 \\
$\quad$ Positive & 260 & 42.5 \\
Serotype among positive & & \\
EV-A* & 146 & 56.1 \\
Coxsackievirus** & 46 & 17.7 \\
Other human RNA enteroviruses & 68 & 26.2 \\
92 selected cases for serotyping & & \\
CV-A10 & 10 & 10.9 \\
CV-A16 & 24 & 26.1 \\
CV-A4 & 2 & 2.2 \\
CV-A6 & 14 & 15.2 \\
CV-B2 & 2 & 2.2 \\
EV-A71 & 32 & 34.8 \\
Human rhinovirus & 2 & 2.2 \\
Unknown & 6 & 6.4 \\
\hline${ }^{*}$ EV-A refers EV-A71 \\
$*$ Coxsackievirus refers CV-A10, CV-A16, CV-A4, CV-A6, CV-B2
\end{tabular}


Table 4 Univariate and multivariable analyses for the identification of factors associated with human enteroviruses among HFMD patients

\begin{tabular}{|c|c|c|c|c|c|c|c|c|}
\hline \multirow[t]{2}{*}{ Characteristic } & \multicolumn{2}{|c|}{ Enterovirus } & \multirow[t]{2}{*}{ OR } & \multirow[t]{2}{*}{$95 \% \mathrm{Cl}$} & \multirow[t]{2}{*}{$p$-value } & \multirow[t]{2}{*}{$\mathrm{OR}_{\mathrm{adj}}$} & \multirow[t]{2}{*}{$95 \% \mathrm{Cl}$} & \multirow[t]{2}{*}{$p$-value } \\
\hline & $n$ & $(\%)$ & & & & & & \\
\hline \multicolumn{9}{|l|}{ Sex } \\
\hline Male & 154 & 59.2 & 1.16 & $0.84-1.60$ & 0.381 & & & \\
\hline Female & 106 & 40.8 & 1.00 & & & & & \\
\hline \multicolumn{9}{|l|}{ Age (years) } \\
\hline$<2$ & 146 & 56.2 & 0.73 & $0.48-1.12$ & 0.153 & & & \\
\hline $2-3$ & 58 & 22.3 & 0.68 & $0.42-1.12$ & 0.130 & & & \\
\hline$>3$ & 56 & 21.5 & 1.00 & & & & & \\
\hline \multicolumn{9}{|l|}{ Residential area } \\
\hline Rural & 150 & 57.7 & 1.00 & & & & & \\
\hline Municipal & 110 & 42.3 & 0.99 & $0.71-1.37$ & 0.940 & & & \\
\hline \multicolumn{9}{|c|}{ Participated in a group activity 2 weeks before disease onset } \\
\hline No & 66 & 25.4 & 0.76 & $0.52-1.11$ & 0.150 & & & \\
\hline Yes & 194 & 74.6 & 1.00 & & & & & \\
\hline \multicolumn{9}{|l|}{ Breastfeeding } \\
\hline No & 14 & 5.4 & 2.78 & $1.20-6.43$ & 0.017 & 3.74 & $1.53-9.10$ & $0.004^{*}$ \\
\hline$\leq 6$ months & 124 & 47.7 & 2.46 & $1.75-3.46$ & $<0.001^{*}$ & 2.52 & $1.76-3.61$ & $<0.001^{*}$ \\
\hline$>6$ months & 122 & 46.9 & 1.00 & & & 1.00 & & \\
\hline \multicolumn{9}{|l|}{ History of vaccination } \\
\hline Complete and timely & 242 & 93.1 & 1.00 & & & & & \\
\hline Incomplete or/and not timely & 18 & 6.9 & 0.74 & $0.41-1.36$ & 0.335 & & & \\
\hline \multicolumn{9}{|l|}{ Day time care } \\
\hline Home & 78 & 30.0 & 1.00 & & & & & \\
\hline Days care center & 154 & 59.2 & 1.28 & $0.90-1.83$ & 0.167 & & & \\
\hline School & 28 & 10.8 & 1.41 & $0.79-2.53$ & 0.243 & & & \\
\hline \multicolumn{9}{|l|}{ Congenital disease } \\
\hline No & 248 & 95.4 & 1.00 & & & & & \\
\hline Yes & 12 & 4.6 & 0.90 & $0.43-1.90$ & 0.778 & & & \\
\hline \multicolumn{9}{|l|}{ Regularly drug use } \\
\hline No & 254 & 97.7 & 1.00 & & & & & \\
\hline Yes & 6 & 2.3 & 2.06 & $0.57-7.36$ & 0.268 & & & \\
\hline \multicolumn{9}{|l|}{ Family member (persons) } \\
\hline$<4$ & 136 & 52.3 & 1.00 & & & & & \\
\hline $4 \quad-7$ & 98 & 37.7 & 1.24 & $0.88-1.74$ & 0.225 & & & \\
\hline$>7$ & 26 & 10.0 & 1.52 & $0.84-2.72$ & 0.164 & & & \\
\hline \multicolumn{9}{|c|}{ Family members $<6$ years old (persons) } \\
\hline$\leq 2$ & 248 & 95.4 & 1.00 & & & & & \\
\hline$>2$ & 12 & 4.6 & 1.02 & $0.47-2.19$ & 0.967 & & & \\
\hline \multicolumn{9}{|l|}{ History of HFMD previous year } \\
\hline No & 228 & 87.7 & 1.00 & & & & & \\
\hline Yes & 32 & 12.3 & 0.93 & $0.58-1.51$ & 0.780 & & & \\
\hline \multicolumn{9}{|l|}{ Religion } \\
\hline Buddhism & 256 & 98.5 & 1.49 & $0.44-5.00$ & 0.520 & & & \\
\hline Christianity & 4 & 1.5 & 1.00 & & & & & \\
\hline
\end{tabular}


Table 4 Univariate and multivariable analyses for the identification of factors associated with human enteroviruses among HFMD patients (Continued)

\begin{tabular}{|c|c|c|c|c|c|c|c|c|}
\hline \multirow[t]{2}{*}{ Characteristic } & \multicolumn{2}{|c|}{ Enterovirus } & \multirow[t]{2}{*}{$\mathrm{OR}$} & \multirow[t]{2}{*}{$95 \% \mathrm{Cl}$} & \multirow[t]{2}{*}{$p$-value } & \multirow[t]{2}{*}{$\mathrm{OR}_{\text {adj }}$} & \multirow[t]{2}{*}{$95 \% \mathrm{Cl}$} & \multirow[t]{2}{*}{$p$-value } \\
\hline & $n$ & $(\%)$ & & & & & & \\
\hline \multicolumn{9}{|l|}{ Father's occupation } \\
\hline Unemployed & 32 & 12.3 & 1.00 & & & & & \\
\hline Government employee & 6 & 2.3 & 0.35 & $0.13-1.01$ & 0.051 & & & \\
\hline armer & 56 & 21.5 & 0.69 & $0.38-1.25$ & 0.220 & & & \\
\hline Daily wage employee & 132 & 50.8 & 0.83 & $0.48-1.41$ & 0.480 & & & \\
\hline Other & 34 & 13.1 & 0.82 & $0.43-1.59$ & 0.557 & & & \\
\hline \multicolumn{9}{|l|}{ Mother's occupation } \\
\hline Unemployed & 50 & 19.2 & 1.00 & & & 1.00 & & \\
\hline Government employees & 6 & 2.3 & 1.18 & $0.42-3.32$ & 0.754 & 0.95 & $0.33-2.74$ & 0.946 \\
\hline Farmer & 46 & 17.7 & 1.75 & $1.06-2.90$ & $0.030^{*}$ & 1.88 & $1.11-3.16$ & $0.018^{*}$ \\
\hline Daily wage employee & 114 & 43.9 & 2.28 & $1.50-3.47$ & $<0.001^{*}$ & 2.18 & $1.41-3.37$ & $<0.001^{*}$ \\
\hline Unprofessional skilled job & 44 & 16.9 & 2.47 & $1.45-4.23$ & $0.001^{*}$ & 2.64 & $1.52-4.61$ & $0.001^{*}$ \\
\hline \multicolumn{9}{|l|}{ Major caregiver } \\
\hline Father & 10 & 3.9 & 1.00 & & & & & \\
\hline Mother & 122 & 46.9 & 0.22 & $0.07-0.71$ & $0.011^{*}$ & & & \\
\hline Relative & 92 & 35.4 & 0.34 & $0.10-1.10$ & 0.072 & & & \\
\hline Father and mother & 36 & 13.8 & 1.03 & $0.28-3.83$ & 0.966 & & & \\
\hline \multicolumn{9}{|l|}{ Marital status of caregiver } \\
\hline Single & 8 & 3.1 & 1.00 & & & & & \\
\hline Married & 230 & 88.4 & 0.92 & $0.36-2.36$ & 0.855 & & & \\
\hline Divorce & 22 & 8.5 & 0.98 & $0.33-2.91$ & 0.974 & & & \\
\hline \multicolumn{9}{|l|}{ Education level of caregiver } \\
\hline Not educated & 68 & 26.2 & 1.00 & & & & & \\
\hline Primary school & 82 & 31.5 & 1.33 & $0.87-2.03$ & 0.185 & & & \\
\hline Secondary school & 34 & 13.1 & 1.10 & $0.65-1.88$ & 0.716 & & & \\
\hline High school & 32 & 12.3 & 0.65 & $0.39-1.10$ & 0.108 & & & \\
\hline Vocational school or higher & 44 & 16.9 & 2.64 & $1.49-4.68$ & $0.001^{*}$ & & & \\
\hline \multicolumn{9}{|c|}{ Daily cleaning of food and drink containers } \\
\hline No & 6 & 2.3 & 1.00 & & & & & \\
\hline Yes & 254 & 97.7 & 3.38 & $1.37-8.33$ & $0.008^{*}$ & & & \\
\hline
\end{tabular}

*Statistically significant at $\alpha=0.05$

experiencing lethargy and malaise than those with EV-A71 and other human enterovirus (Table 5).

\section{Discussion}

Children less than 2 years old are the major vulnerable population for HFMD infection in northern Thailand. However, the proportion of diagnosed HFMD cases was not significantly different between sexes. The rainy season is the epidemic period during the year. The incidence rates in northern Thailand are higher than the Thai national rate and are also higher than other regions in the
Asia-Pacific Region, such as Vietnam [37], Taiwan [38], China [39], and Hong Kong [40]. Based on these reports, more than half of HFMD cases are the EV-A serotype. A closer look into the sub-serotype in 92 selected cases showed that EV-A71 was dominant in the enterovirus group, and CV-A16 was dominant in the coxsackievirus group. The average duration from disease onset to the end of its course was 4.04 days, and the average number of days after the onset of disease before visiting a doctor was 1.70 days. Most HFMD patients attended the outpatient department. A history of breastfeeding $\leq 6$ months and the 
Table 5 Associations of the serotype with the signs and symptoms of HFMD ( $n=576$ cases, missing 36 cases)

\begin{tabular}{|c|c|c|c|c|c|c|c|}
\hline Signs and symptoms & & $\begin{array}{l}\text { Coxsackievirus } \\
n(\%)\end{array}$ & $\begin{array}{l}\text { Enterovirus A71 } \\
n(\%)\end{array}$ & $\begin{array}{l}\text { Other human } \\
\text { enterovirus } \\
n(\%)\end{array}$ & $\begin{array}{l}\text { Nonhuman } \\
\text { enterovirus } \\
n(\%)\end{array}$ & $x^{2}$ & $p$-value \\
\hline \multirow[t]{2}{*}{ Rash on palms and soles } & Yes & $36(94.7)$ & $114(81.4)$ & $52(83.9)$ & $288(85.7)$ & 4.437 & 0.218 \\
\hline & No & $2(5.3)$ & $26(18.6)$ & $10(16.1)$ & $48(14.3)$ & & \\
\hline \multirow{2}{*}{$\begin{array}{l}\text { Rash on buttocks, } \\
\text { knee and elbow }\end{array}$} & Yes & $14(36.8)$ & $20(14.3)$ & $26(41.9)$ & $106(31.6)$ & 22.026 & $<0.001^{*}$ \\
\hline & No & $24(63.2)$ & $120(85.7)$ & $36(58.1)$ & $230(68.4)$ & & \\
\hline \multirow[t]{2}{*}{ Fever } & Yes & $24(63.2)$ & $76(54.3)$ & $56(90.3)$ & $214(63.7)$ & 24.462 & $<0.001^{*}$ \\
\hline & No & $14(36.8)$ & $64(45.7)$ & $6(9.67$ & $122(36.3)$ & & \\
\hline \multirow[t]{2}{*}{ Sore throat or mouth ulcer } & Yes & $36(94.7)$ & $130(92.9)$ & $54(87.1)$ & $274(81.6)$ & 13.258 & $0.004^{*}$ \\
\hline & No & $2(5.3)$ & $10(7.1)$ & $8(12.9)$ & $62(18.4)$ & & \\
\hline \multirow[t]{2}{*}{ Weakness } & Yes & $10(26.3)$ & $14(10.0)$ & $8(12.9)$ & $58(17.3)$ & 7.686 & 0.053 \\
\hline & No & $28(73.7)$ & $126(90.0)$ & $54(87.1)$ & $278(82.7)$ & & \\
\hline \multirow[t]{2}{*}{ Anorexia } & Yes & $20(52.6)$ & $58(41.4)$ & $20(32.3)$ & $130(38.7)$ & 4.408 & 0.221 \\
\hline & No & $18(47.4)$ & $82(58.6)$ & $42(67.7)$ & $206(61.3)$ & & \\
\hline \multirow[t]{2}{*}{ Diarrhea } & Yes & $2(5.3)$ & $6(4.3)$ & $2(3.2)$ & $32(9.5)$ & 5.452 & $0.129^{a}$ \\
\hline & No & $36(94.7)$ & $134(95.7)$ & $60(96.8)$ & $304(90.5)$ & & \\
\hline \multirow[t]{2}{*}{ Lethargy } & Yes & $10(26.3)$ & $10(7.1)$ & $8(12.9)$ & $30(8.9)$ & 13.433 & $0.004^{*}$ \\
\hline & No & $28(73.7)$ & $130(92.9)$ & $54(87.1)$ & 306 (91.1) & & \\
\hline \multirow[t]{2}{*}{ Malaise } & Yes & $6(15.8)$ & $4(2.9)$ & $6(9.7)$ & $6(1.8)$ & 18.967 & $<0.001^{*, a}$ \\
\hline & No & $32(84.2)$ & $136(97.1)$ & $56(90.3)$ & $330(98.2)$ & & \\
\hline \multirow[t]{2}{*}{ Vomiting } & Yes & $4(10.5)$ & $4(2.9)$ & $4(6.5)$ & $24(7.1)$ & 4.855 & $0.168^{a}$ \\
\hline & No & $34(89.5)$ & 136 (97.1) & $58(93.5)$ & 312 (92.9) & & \\
\hline
\end{tabular}

*Statistically significant at $a=0.05$

${ }^{\text {a}}$ Fisher's exact test

occupation of the parents were associated with enterovirus HFMD infection among children. Children who had mother who worked as farmers, daily wage employee, and unprofessional skilled job had greater chance of EV-associated HFMD than children who had mother as unemployed. Patients with coxsackievirus and other human enteroviruses had a greater chance of having a rash on their buttocks than those with EV-A71. Patients with coxsackievirus had a greater chance of experiencing lethargy and malaise than those with EV-A71 and other human enterovirus.

In our study, most of the infected persons were children aged less than 2 years old, which is consistent with the study by Rao et al. [41] that presented the most infected persons with HFMD in India. Wang et al. [42] also supported that children less than 2 years old were the most vulnerable population for HFMD in China. Regarding sex, in our study, more than half of the patients were male (57.4\%), which is similar to the study by Zou et al. [43], which reported that most of the HFMD-infected children in China were male, accounting for $60.0 \%$ of all cases.

Inta et al. [29] and Upala et al. [30] reported that the specific climate characteristics of the northern region of
Thailand, particularly the temperature, moisture, air pressure, and rainfall amount, contributed to the epidemic of HFMD. In our study, the highest number of HFMD episodes was reported in the rainy season (JuneOctober). $\mathrm{Xu}$ et al. [44] found that environmental temperature was the key contributing factor to the number of HFMD cases in southern China.

Suliman et al. [45] reported that the occupation and behaviors of parents were associated with HFMD infection among preschool children. This finding is consistent with our study, which found that children with parents in some occupations accounted for a greater proportion of children with diagnoses of HFMD than those with parents in other occupations.

Many studies have reported that human enteroviruses classified from HFMD patients have different serotype proportions. In our study, we found that $56.1 \%$ of detected pathogens were EV-A71, and $17.7 \%$ were coxsackievirus. This finding was consistent with that of the study by He et al. [46], who reported that EV-A71 accounted for $41.9 \%$ of HFMD cases among young children in southern China, whereas a study in Guangdong, China, reported that only $22.4 \%$ of HFMD cases were classified as EV-A71 positive, 
and $23.0 \%$ were coxsackievirus positive [47]. Interestingly, $\mathrm{Li}$ et al. [48] reported that CV-A6 played a dominant role in several outbreaks in China and many other countries in Asia. Our study also found that $15.2 \%$ of HFMD cases were CV-A6 positive.

In this study, we found that $42.5 \%$ of patients with a diagnosis of HFMD were positive for human enterovirus, but $\mathrm{He}$, et al. [46] reported that almost $91.3 \%$ of cases were positive for human enterovirus. A study in Shanghai reported that among 614 HFMD patients, only 19.9\% were EV-A71 positive [47]. Ganorkar et al. [6] reported that the main serotype of CV among HFMD patients was CV-A16. This finding was consistent with our study, which showed that CV-A16 was the main sub-serotype followed by CV-A6.

Inta et al. [29] reported that having a history of breastfeeding for more than 6 months was a protective factor for HFMD in school children in Thailand. The study in Vietnam also reported that socioeconomic status, including breastfeeding of infants, was a protective factor for HFMD [37]. Moreover, a neonatal mouse model used to assess the effectiveness of breastfeeding found that breastfeeding played a protective role in HFMD, which could be due to the IgG acquired from mothers during breastfeeding [49]. This finding is consistent with our study, which found that children with no history of breastfeeding and those who breastfed for less than 6 months had a greater chance of acquiring an HFMD infection.

Wei et al. [50] reported that patients with EV-A71 infection had a longer duration of high fevers and a longer duration of illness than patients with HFMD of other causes in China. Zou [43] reported that EV-A71 was associated with severe cases of HFMD in Guangdong, China. In contrast, our study found that some clinical features, such as rash, mouth ulcers, and fever, are related to coxsackieviruses. A prospective cohort study conducted in Cambodia reported that EV-A71 was associated with severe clinical signs and symptoms among HFMD-infected children, particularly those with nervous system complications [51]. EV-A71 is a predominant serotype of an HFMD outbreak in Spain and is associated with severe clinical signs such as brainstem symptoms [52]. A study in China reported that the severity of HFMD is not only impacted by the virus serotype but also the age and comorbidity of patients [45]. Parental behaviors are also associated with the severity of the disease [45]. Ooi et al. reported that most severe cases of HFMD were caused by EVA-71 [53].

Some limitations in the study may affect the study results. Thirteen out of ninety-six specimens that were collected from the early cases of HFMD outbreak were stored for more than $24 \mathrm{~h}$ at the original institute before reaching the laboratory due to the distance between the hospitals and the laboratory. The working hours of the laboratory are only Monday to Friday, but outbreaks sometimes occurred during the weekend. The researchers addressed this problem by initiating a proper storage procedure in the hospital to maintain the quality of the specimens.

In our study, the laboratory was in Chiang Rai Province. Therefore, the specimens obtained from hospitals in Pha Yao Province were difficult to transport on time. Additionally, seven parents could not remember whether their children were previously diagnosed with HFMD, and four parents could not provide an accurate history of congenital disease in their children during the interview. Finally, this information was obtained from medical records after acquiring approval from the parents and the doctors. However, participants who responded with "no previous diagnosis of HFMD" may have introduced recall bias, as the medical records of those participants were not investigated. And 36 cases (5.8\%) of the participants could not obtain the information regarding the clinical signs and symptoms. However, the missed data might not impact the analysis since there were a few number (only 5.8\%), and the characteristics of missing data similar with those remaining in the analysis.

In addition, only 9 hospitals have a pediatric department. Therefore, specimen collection in the remaining 5 hospitals was completed by medical technicians, who are healthcare professionals and have completed a four-year university program focusing on training in laboratory work, including specimen collection from patients.

Another potential limitation in this study is selection bias, because some members of the study population did not meet the criteria to access healthcare services free of charge. Individuals with a Thai ID card were more likely to access medical care than those without a Thai ID card. The selection bias may extend to other populations with specific characteristics. For instance, parents of children aged 2-4 years tended to seek medical care more often than other individuals [54].

Last, we used throat swabs to collect specimens for detection in the laboratory instead of stool. During the pilot test, we collected stool samples, but we found that this method was not effective in young children, as specimens were difficult to obtain.

\section{Conclusion}

Northern Thailand is presented as an epidemic area of HFMD particularly in Chiang Rai and Pha Yao provinces. A number of infected persons have been reported through several episodes of HFMD outbreak. EV-A71, CV-A16, and CV-A6 are major causes of HFMD in children $<6$ years. Less of breastfeeding time and unprofessional job of their mother are the factors associated with HFMD in their children. Patients with coxsackievirus and other human enteroviruses have a variety of clinical 
signs and symptoms than those with EV-A71. All children should be provided in breastfeeding from their mother at least 6 months after getting birth. Public health interventions should be promoted for mothers in child caring skills to prevent HFMD particularly those who are working unprofessional job sectors.

\section{Additional files}

Additional file 1: Questionnaire. It is a set of questions which was used for collecting data in the project. It was developed by authors, and never been published elsewhere. (PDF $89 \mathrm{~kb}$ )

Additional file 2: HFMD_Data $t$ is the coded data of the HFMD project which was conducted in northern Thailand. (XLSX $233 \mathrm{~kb}$ )

\section{Abbreviations}

CV: Coxsackievirus; DCC: Day care center; EPI: Expanded program of Immunization; EV: Enterovirus; G-6-PD: Glucose-6-phosphate dehydrogenase deficiency; HFMD: Hand, foot and mouth disease; ICD-10: International classification of disease version 2010; ID: Identification card; IgG: Immunoglobulin G; IOC: Item-objective congruence; IPD: Inpatient department; OPD: Outpatient department; PCR: Polymerase chain reaction; RT-PCR: Reverse transcriptase polymerase chain reaction; SD: Standard deviation; WHO: World Health Organization

\section{Acknowledgments}

The author is grateful to the National Research Council of Thailand, Mae Fah Luang University, and the Center of Excellence for the Hill-tribe Health Research for supporting the grant. The author would like to thank all the parents for their participation, the staff of the 14 hospitals, and the laboratory staff from Chiang Rai Medical Laboratory Center.

\section{Funding}

The National Research Council of Thailand and Mae Fah Luang University funded this work (No 59207041012).

The funders had no role in the design of the study and collection, analysis, and interpretation of data and in writing the manuscript.

\section{Availability of data and materials}

The datasets used and/or analyzed during the current study are available from the Additional files.

\section{Authors' contributions}

PU designed the study; collected and analyzed the data; drafted the manuscript; and approved the final version. TA conceived and designed this study; collected, analyzed and interpreted the data; drafted the manuscript; and approved the final version of the manuscript. WS performed the laboratory tests, drafted the manuscript and approved the final version of the manuscript. NK performed the laboratory tests, interpreted the laboratory results, drafted the manuscript, and approved the final version. RT collected the data, drafted the manuscript and approved the final version. Cl and RT collected the data, drafted the manuscript and approved the final version.

\section{Authors' information}

Dr. Tawatchai Apidechkul is the Assistant Professor and Director of the Center of Excellence for the Hill-tribe Health Research and trained in infectious disease epidemiology at Emory University in the United States under the Hubert H. Humphrey (Fulbright) program and in the Global Health Delivery Intensive Program from Harvard University. Dr. Wipob Suttana earned his Ph.D. in Medical Technology and has worked on infectious diseases for 6 years. Dr. Niwed Kullawong earned his Ph.D. in molecular genetics and genetic engineering from Mahidol University, Thailand, and has worked in this field for almost 3 years. Panupong Upala, Ratipark Tamornpark, and Chadaporn Inta earned their M.Sc (Epidemiology) from Mae Fah Luang University in Thailand.

\section{Ethics approval and consent to participate}

All the research protocols and procedures were approved by the Mae Fah Luang University Research Ethics Committee on Human Research (No.007/ 2559), The Human Research Ethics Committee from Chiang Rai Provincial Public Health Office (No 018/2559), and The Human Research Ethics Committee from Pha Yao Provincial Public Health Office (No. 005/2559). All parents were asked to help provide information, collect throat swabs from their children, and sign the informed consent form on behalf of their children before starting the data collection process.

\section{Consent for publication}

Not applicable.

\section{Competing interests}

The authors declare that they have no competing interests.

\section{Publisher's Note}

Springer Nature remains neutral with regard to jurisdictional claims in published maps and institutional affiliations.

Received: 6 October 2018 Accepted: 26 November 2018

Published online: 06 December 2018

\section{References}

1. World Health Organization (WHO). A guide to clinical management and public health response for hand, foot and mouth disease (HFMD). 2011. http://www. wpro.who.int/publications/docs/GuidancefortheclinicalmanagementofHFMD.pdf

2. Wang H, Du Z, Wang X, Liu Y, Yuan Z, Liu Y, et al. Detecting the association between meteorological factors and hand, foot, and mouth disease using spatial panel data models. International Journal of Infectious Disease. 2015; 34:66-70.

3. Gui J, Liu Z, Zhang T, Hua Q, Jiang Z, Chen B, et al. Epidemiological characteristic and spatial-temporal clusters of hand foot and mouth disease in Zhejiang Province, China, 2008-2012. PLoS One. 2015;10(9):e0139109.

4. Wu X, Hu S, Kwaku AB, Li Q, Luo K, Zhou Y, et al. Spatio-temporal clustering analysis and its determinants of hand, foot and mouth disease in Hunan, China, 2009-2015. BMC Infect Dis. 2017;17:645.

5. Qi H, Chen Y, Xu D, Su H, Zhan L, Xu Z, et al. Impact of meteorological factors on the incidence of childhood hand, foot, and mouth disease (HFMD) analyzed by DLNMs-based time series approach. Infectious Diseases of Poverty. 2018;7(1):7.

6. Ganorkar NN, Patil PR, Tikute SS, Gopalkrishna V. Genetic characterization of enterovirus strains identified in hand, foot and mouth disease (HFMD): emergence of B1C, C1 subgenotypes, E2 sublineage of CVA16, EV71 and CVA6 strains in India. Infect Genet Evol. 2017;54:192-9.

7. Cabrerizo M, Tarrago D, Munoz-Almagro C, Amo DE, Dominguez-Gil M, Eiros $\mathrm{JM}$, et al. Molecular epidemiology of enterovirus 71, coxsackievirus A16 and A6 associated with hand, foot and mouth disease in Spain. Clin Microbiol Infect. 2014;20(3):0150-6.

8. Mao LX, Wu B, Bao WX, Han FA, Xu L, Ge QJ, et al. Epidemiology of hand, foot, and mouth disease and genotype characterization of enterovirus 71 in Jiangsu. China Journal of Clinical Virology. 2010;49(2):100-4.

9. Chen M, Ju Y, Chen M, Xie Z, Zhou K, Tan Y, et al. Epidemiological and genetic characteristics of EV71 in hand foot and mouth disease in Guangxi, southern China, from 2010 to 2015. PLoS One. 2017;12(12):e0188640.

10. Zheng G, Cao J, Yu J, Zhang Z, Liu Q, Chen J. Risk factors for death in children with critical and severe hand-foot-and-mouth disease in Chongqing, China: an observational study. Medicine (Baltimore). 2017;96(49):e8934.

11. Owatanapanich S, Wutthanarungsan $R$, Jaksupa W, Thisyakorn U. Risk factors for server hand, foot, and mouth disease. Southeast Asian J Trop Med Public Health. 2015;46(3):449-59.

12. World Health Organization (WHO). Fact sheet: Hand, foot and mouth disease (HFMD) 2017. http://www.wpro.who.int/emerging_diseases/HFMD/en/

13. Li M, Duan $Y$, Yang $X$, Yang $Q$, Pang B, Wang $Y$, et al. Intradermal injection of a fractional dose of an inactivated HFMD vaccine elicits similar protective immunity to intramuscular inoculation of a full dose of an $\mathrm{AL}(\mathrm{OH})_{3^{-}}$ adjuvanted vaccine. Vaccine. 2017;35:3709-17.

14. Yee PTI, Laa PC. Impact of genetic changes, pathogenicity and antigenicity on enterovirus-A71 vaccine development. Virology. 2017;506:121-9.

15. Lyu K, Chen R. Achievements, challenges and prospects for the development of broadly protective multivalent vaccines and therapeutic 
antibodies against hand, foot and mouth disease. Science Bulletin. 2015; 60(15):1305-15.

16. Liu $\mathrm{Q}$, Tong $\mathrm{X}$, Huang Z. Toward broadly protective polyvalent vaccines against hand, foot and mouth disease. Microbes Infect. 2015;17(2):155-62.

17. Zhou Y, Zhang C, Liu Q, Gong S, Geng L, Huang Z. A virus-like particle vaccine protects mice against coxsackievirus A10 lethal infection. Antivir Res. 2018;152:124-30.

18. Yang B, Liu F, Liao Q, Wu P, Chang Z, Huang J, et al. Epidemiology of hand, foot and mouth disease in China, 2008 to 2015 prior to the introduction of EV-A71 vaccine. Euro surveill. 2017;22(50).

19. World Health Organization (WHO). Fact sheet: Hand, Foot and Mouth Disease (HFMD) 2016. 2016. www.wpro.who.int/emerging_diseases/hfmd_ biweekly_20170103rev.pdf?ua=1

20. Bureau of Epidemiology. 506 surveillance system report. 2017. www.boe. moph.go.th/boedb/surdata/506wk/y60/d71_5360.pdf

21. Linsuwanon P, Puenpa J, Huang SW, Wang YF, Mauleekoonphairoj J, Wang $J R$, et al. Epidemiology and seroepidemiology of human enterovirus 71 among Thai populations. J Biomed Sci. 2014;21(1):16. https://doi.org/10. 1186/1423-0217-21-16

22. Tangcharoensathien V, Witthayapipopsakul W, Panichkriangkrai W, Patcharanarumol W, Mills A. Health systems development in Thailand: a solid platform for successful implementation of universal health coverage. PlumX Metrics. 2018; https://doi.org/10.1016/S0140-6736(18)30198-3.

23. Chaveepojnkamjorn W, Pichainarong N. Behavioral factors and malaria infection among the migrant population, Chiang Rai Province. J Med Assoc Thail. 2005;88(9):1293-301.

24. Chiang Rai Times. Migrant Workers in Thailand Victims of a Broken System. 2017. www.chiangraitimes.com/migrant-workers-in-thailand-victims-of-abroken-system.html

25. The hill tribe welfare and development center, Chiang Rai province. Hill tribe population. In: The hill tribe welfare and development center. Chiang Rai: Ministry of Interior; 2017.

26. Apidechkul T, Wongnuch P, Sittisarn S, Ruanjai T. Health situation of Akha hill tribe in Chiang Rai Province, Thailand. Journal of Public Health and Development. 2016;14(1):77-97.

27. Tamornpark R, Apidechkul T, Upala P, Inta C. Factors associated with type 2 diabetes mellitus among the elderly hill tribe population in Thailand. Southeast Asian Journal Trop Med Public Health. 2017;48(5):1072-82.

28. Sugawara T, Fujimoto T, Ohkusa Y, Sugishita Y, Konagaya M, Sugiura $H$, et al. The possibility of outbreak control by real-time surveillance with PCR method performed immediately-a case study of hand foot and mouth disease outbreak in a day care facility for children. Kansenshogaku Zasshi. 2012;86(4):405-10.

29. Inta C, Apidechkul T, Sittisarn S, Wongnuch P, Laor P, Suma Y, et al. Factors associated with hand foot mouth disease among children in day care center, Chiang Rai, Thailand. Asian Pacific Journal of Tropical Disease. 2017;7(7):391-5

30. Upala P, Apidechkul T, Suttana W, Aimkosa R. Epidemiology of hand foot mouth disease in northern Thailand in 2016: a prospective cohort study. Asian Pacific Journal of Tropical Disease. 2017;7(6):321-6.

31. Ministry of Public Health, Thailand. Characteristics of HFM outbreak in Thailand, 2013-2016. 2016. http://thaigcd.ddc.moph.go.th/uploads/pdf/baby/ 13.7.58/Measure_HFM.pdf

32. World Health Organization (WHO). International statistical classification of disease and related health problems (ICD-10). 2016. http://www.who.int/ classifications/icd/en/

33. Centers for Disease Control and Prevention (CDC). Outbreak case definitions. 2012. https://www.cdc.gov/urdo/downloads/casedefinitions.pdf

34. Bureau of Epidemiology, Ministry of Public Health. Surveillance system. 2018. http://203.157.15.110/boe/home.php

35. Beak K, Park K, Jung E, Chung E, Park J, Choi H, et al. Molecular and epidemiological characterization of enteroviruses isolated in Chungnam, Korea from 2005 to 2006. J Microbiol Biotechnol. 2009;19(9):1005-64.

36. Chio HK, Lee NY, Lee H, Kim HS, Seo JW, Hong YM, et al. Enterovirus 71associated hand, foot and mouth diseases with neurologic symptoms, a university hospital experience in Korea, 2009. Korean Journal of Pediatrics. 2010;53(5):639-43.

37. Phung D, Nguyen HX, Nguyen HLT, Do CM, Tran QD, Chu C. Spatiotemporal variation of hand-foot-mouth disease in relation to socioecological factors: a multiple-province analysis in Vietnam. Sci Total Environ. 2018;610-611:983-91.

38. Chen $P$, Wang $H$, Tao Z, Xu A, Lin X, Zhou N, et al. Multiple transmission chains of coxsackievirus A4 co-circulating in China and neighboring countries in recent years: phylogenetic and spatiotemporal analyses based on virological surveillance. Mol Phylogenet Evol. 2018;118:23-31.

39. Huang DC, Wang JF. Monitoring hand, foot and mouth disease by combining search engine query data and meteorological factors. Sci Total Environ. 2018;612:1293-9.

40. Chan JH, Law CK, Hamblion E, Fung H, Rudge J. Best practices to prevent transmission and control outbreaks of hand foot and mouth disease in childcare facilities: a systematic review. Hong Kong Med J. 2017;23:177-90.

41. Rao DC, Naidu JR, Maiya PP, Babu A, Bailly JL. Large-scale HFMD epidemics caused by Coxsackievirus A16 in Bangalore, India during 2013 and 2015. Infect Genet Evol. 2017:55:228-35.

42. Wang C, Zhou S, Xue W, Shen L, Huang W, Zhang Y, et al. Comprehensive virome analysis reveals the complexity and diversity of the viral spectrum in pediatric patients diagnosed with severe and mild hand foot and mouth disease. Virology. 2018;518:116-25.

43. Zou XN, Zhang XZ, Wang B, Qiu YT. Etiologic and epidemiologic analysis of hand, foot, and mouth disease in Guangzhou city: a review of 4,753 cases the. Braz J Infect Dis. 2012;16(5):457-65.

44. Xu J, Zhao D, Su H, Xie M, Cheng J, Wang X, et al. Impact of temperature variability on childhood hand, foot and mouth disease in Huainan. China Public Health. 2016;134:86-94.

45. Suliman Q, Said SM, Zulkefli NAM. Predictors of preventive practices towards HFMD among mothers of preschool children in Klang district. Mal J Med Health Sci. 2017;13(3):21-32.

46. He SJ, Han JF, Ding XX, Wang YD, Qin CF. Characterization of enterovirus 71 and coxsackievirus A16 isolated in hand, foot, and mouth disease patients in Guangdong, 2010. International Journal of Infectious Disease. 2013;17(11): e1025-30.

47. Zeng M, El Khatib NF, Tu S, Ren P, Xu S, Zhu Q, et al. Seroepidemiology of enterovirus 71 infection prior to the 2011 season in children in Shanghai. J Cli Virol. 2012;53(4):285-9.

48. Li JL, Yuan J, Yang F, Wu ZQ, Hu YF, Xue Y, et al. Epidemic characteristics of hand, foot, and mouth disease in southern China, 2013: Coxsackievirus A6 has emerged as the predominant causative agent. J Infect. 2014;69(30):299-303.

49. Yang L, Mao Q, Li S, Gao F, Zhao H, Liu Y, et al. A neonatal mouse model for the evaluation of antibodies and vaccines against coxsackievirus A6. Antivir Res. 2016;134:50-7.

50. Wei R, Xu L, Zhang N, Zhu K, Yang J, Yang C, et al. Elevated antigen-specific Th2 type response is associated with the poor prognosis of hand, foot and mouth disease. Virus Res. 2013;177(1):62-5.

51. Crabol Y, Pean P, Mey C, Duong V, Richner B, Laurent D, et al. A prospective, comparative study of severe neurological and uncomplicated hand, foot and mouth forms of pediatric enterovirus 71 infections. International Journal of Infectious Disease. 2017;59:69-76.

52. Casas-Alba D, de Sevilla MF, Valero-Rello A, Fortuny C, Garcia-Garcia JJ, Ortez $C$, et al. Outbreak of brainstem encephalitis associated with enterovirus-A71 in Catalonia, Spain (2016): a clinical observational study in a children's reference Centre in Catalonia. Clin Microbiol Infect. 2017:23(11):874-81.

53. Ooi MH, Wong SC, Lewthwaite P, Cardosa MJ, Solomon T. Clinical features, diagnosis, and management of enterovirus 71. Neurology. 2010;9(11):1097-105.

54. Wang X, Wu X, Jia L, Li X, Li J, Li S, et al. Estimating the number of hand foot and mouth disease amongst children aged under-five in Beijing during 2012, based on a telephone survey of health care seeking behaviors. BMC Infect Dis. 2014;14:437. https://doi.org/10.1186/1471-2334-14-437.

\section{Ready to submit your research? Choose BMC and benefit from:}

- fast, convenient online submission

- thorough peer review by experienced researchers in your field

- rapid publication on acceptance

- support for research data, including large and complex data types

- gold Open Access which fosters wider collaboration and increased citations

- maximum visibility for your research: over $100 \mathrm{M}$ website views per year

At BMC, research is always in progress.

Learn more biomedcentral.com/submissions 